\title{
Duodenal ulceration in children ${ }^{1}$
}

\author{
J. C. MILLIKEN
}

From Sir Patrick Dun's Hospital, Dublin

SYNOPSIS Duodenal ulceration may occur in children although the symptoms may be atypical; pain at night is a common occurrence. Conservative but energetic treatment is advocated.

Until recent years the occurrence of peptic ulceration in children had been regarded as a rarity, but the condition is now being diagnosed with increasing frequency, largely due to a more general appreciation of the existence of the problem. During the early part of this century Adler (1907), Dickey (1926), and Oldfield (1932) published reports of one or more cases of ulcer in childhood, and in 1941 Bird, Limper, and Mayer reviewed the literature available on the subject up to that date, representing a total of 243 patients. As recently as 1953 Aye reported four cases, and about the same time McAleese and Sieber (1953) recorded 16 cases which were seen over a period of 13 years at the Children's Hospital of Pittsburg.

The only report of a large series in the British Isles is that of Goldberg (1957) who presented 20 cases which were diagnosed over a period of five years at Booth Hall Hospital, Manchester. Since then Muggia and Spiro (1959) have reviewed 24 patients seen over 12 years at the Grace Newhaven Hospital, U.S.A., and in 1960 Michener, Kennedy, and DuShane presented 109 cases of infantile and childhood ulcer observed at the Mayo Clinic during the period 1930 to 1957. Ramirez Ramos, Kirsner, and Palmer (1960) recorded 32 patients seen at the University of Chicago clinics, and in 1961 Fallstrom and Reinand reviewed 36 children admitted to the Gothenberg Children's Hospital with peptic ulceration over the previous 15 years.

It is the purpose of this paper to present a series of 35 children with duodenal ulceration, all of whom have been diagnosed and treated at this hospital during the past 10 years.

\section{DEFINITION AND CLASSIFICATION}

Childhood ulceration is accepted as having occurred in cases in which the diagnosis has been established before the patient has reached the age of 16 years,

${ }^{1}$ This paper is based on a thesis accepted for the M.D. degree of Dublin University, and on a communication given to the annual meeting of the Irish Paediatric Association, 1962. and cases are classified according to age into neonatal (birth to 2 weeks), infantile ( 2 weeks to 2 years), childhood (2 to 9 years), and later childhood or adolescent ( 9 to 15 years) groups.

Peptic ulceration in children is also classified on an aetiological basis into primary and secondary. The former group includes all cases in which there is no evidence of a definite predisposing condition. Secondary ulceration may follow burns, severe infections, or cerebral disease.

In addition, the occurrence of acute peptic ulceration during steroid therapy is well recognized (Popert and Davis, 1958), and Goldberg (1954) reported the development of an ulcer in a boy of $6 \frac{1}{2}$ years who was being treated with cortisone for the adrenogenital syndrome. Acute ulceration may also follow aspirin administration and Lorber (1957) recorded the case of a 14-year-old girl who had a major haematemesis while on treatment with prednisolone and Disprin for rheumatic fever. Peptic ulcer in adults may be associated with islet cell tumours of the pancreas, or with hyperactivity of the adrenal or parathyroid glands, and it is possible that instances of these associations may occur in children also.

\section{CLINICAL MATERIAL}

The present series is the result of a review of all the children seen at this hospital during the 10-year period 1953 to 1962 in whom the diagnosis of duodenal ulcer was confirmed before the age of 16 years. Patients diagnosed at a later age, in whom symptoms date from childhood, have been excluded. In every case the diagnosis has been made at operation, or on a strict basis of a combination of clinical features, radiological findings, and response to treatment. All are believed to represent instances of primary ulceration.

AGE AND SEX INCIDENCE There were 35 children, aged from 7 to 15 years. Eight were aged 9 years or 


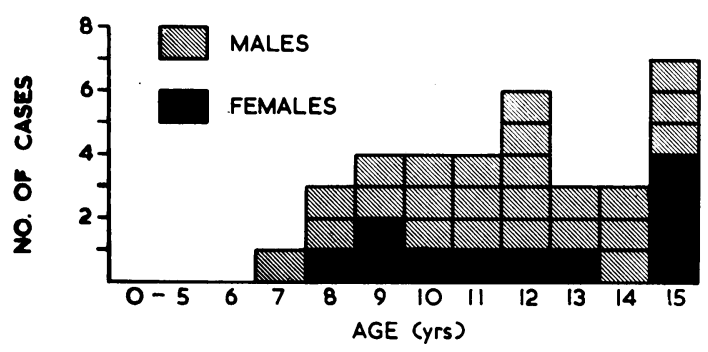

FIG. 1. The combined age and sex ratio in the present series of 35 children aged from 7 to 15 years.

less (childhood group) and 27 were 10 to 15 years old (late childhood or adolescent group).

There were 24 boys and 11 girls, a male preponderance of approximately 2 to 1 . This sex ratio was maintained in the three cases which presented as acute perforations. The combined age and sex incidence is shown in Figure 1.

FAMILY HISTORY In 10 cases there was a definite family history of peptic ulcer. The 17-year-old brother of one child was treated for a perforated duodenal ulcer. One or other parent of five of the children had been treated for confirmed peptic ulceration, in two cases surgically. One boy treated here is the cousin of a child diagnosed at Booth Hall Hospital, and his uncle also has a duodenal ulcer. In three other instances one or more parental siblings were ulcer patients.

\section{INCIDENCE}

It is impossible at present to evaluate the true incidence of peptic ulceration in childhood on the basis of published case reports. However, Muggia and Spiro (1959) noted that while the diagnosis was made only once in a child at the Grace Newhaven Hospital between 1940 and 195220 further cases were seen in the following seven years. Similarly, Goldberg (1957) reported a suspicious yearly increase in the incidence of duodenal ulcer at Booth Hall Hospital, which he attributed to an increased interest in the condition.

In the present series only three of the patients were diagnosed in the first five years, the remainder having been seen since 1957. In fact, the number of acute perforations encountered in the second fiveyear period alone equals the total number of cases seen previously. This appears to support a general clinical impression that childhood ulceration is becoming more common. Fallstrom and Reinand (1961) state that in their opinion a real increase in the incidence is taking place and, although there is insufficient evidence available at present on which to base a firm conclusion regarding trends in incidence, there is no doubt that the true incidence of childhood ulceration is considerably higher than is generally realized.

\section{CLINICAL FEATURES}

The duration of symptoms before diagnosis varied from four weeks to two years. In all of the children the principal symptom was pain. This occurred in periodic attacks lasting several hours at a time.

In the younger patients symptoms were often atypical. Pain was frequently referred to the umbilical region, and rarely had any relation to meals. Many of these patients are diagnosed initially as cases of mesenteric adenitis or appendicular dyspepsia, and three children in this series were submitted to appendicectomy on this basis without remission of symptoms. In later childhood symptoms conformed more to the adult pattern.

Goldberg (1957) remarked on the frequent occurrence of pain at night and regarded this as a significant feature. Sixteen of the children seen here suffered from nocturnal pain and several of them complained that this was the most severe pain of all.

Most of the children complained of anorexia and nausea in association to the pain, although only seven admitted to vomiting when the pain was present. An analysis of the clinical features is shown in Table $\mathbf{I}$.

\section{TABLE I}

CLINICAL FEATURES

\begin{tabular}{lc} 
Symptoms and Signs & No. of Cases \\
\hline Pain & 35 \\
Epigastric & 29 \\
Umbilical & 5 \\
Generalized abdominal & 1 \\
Occurring at night & 16 \\
Relieved by food & 9 \\
Aggravated by food & 2 \\
Unrelated to meals & 24 \\
Vomiting & 7 \\
Local tenderness & 25 \\
Generalized tenderness & 6 \\
Appendicectomy before onset of symptoms & 3 \\
Treated initially by appendicectomy & 3
\end{tabular}

Excluding those patients diagnosed before 1960 in whom symptoms had settled when seen at review, tenderness was invariably present, usually located somewhere between the umbilicus and the xiphoid. In fact, although most previous authors have discounted local tenderness, this feature has been accepted as one of the diagnostic criteria in this series. 
DIAGNOSIS

According to Ramirez Ramos et al. (1960) the most valuable diagnostic procedure is barium meal examination and this was performed in all cases. Goldberg (1957) stated that it is difficult to demonstrate the niche of a duodenal ulcer in children and only four of his patients showed a definite ulcer radiologically. Contrary to this, a definite ulcer crater was demonstrated (repeatedly in two cases) in $16(46 \%)$ of the children in the present series, and in all but two of the remaining 19 gross duodenal deformity was shown.

In one girl there was such intense pylorospasm that it was impossible to visualize the duodenum at all, and after five hours most of the barium was retained in the stomach. She had been treated originally by appendicectomy for the same symptoms. The other patient, in whom only pylorospasm was seen, has had further exacerbations and will require re-admission.

One remarkable fact has been the accuracy with which many of the children seen during the past two years have indicated the duodenum as the site of their pain during screening.

Most previous authors agree that gastric analysis in children is unreliable and Goldberg (1957) found that only one patient of 10 examined showed hyperacidity. McAleese and Sieber (1953) noted similar findings. Standard fractional test meals were performed on 15 children in this series and in only five were significantly raised total acid curves obtained. Also, of 15 patients whose faeces were examined for the presence of occult blood only three showed positive results.

\section{COMPLICATIONS}

Peptic ulceration in children is liable to the same complications as occur in adults. In infancy haemorrhage may be the presenting feature, while ulcers in later childhood are more likely to perforate or produce stenosis. No instance of gross haemorrhage or stenosis occurred in the present series, although three of the children presented with perforations. Two had simple closure of the perforation performed; one of these was a boy with situs inversus totalis, and has been reported previously (Milliken, 1962). The third was a girl of 15 years with a history of four weeks' epigastric pain which became suddenly severe 48 hours before admission. Radiography of the erect abdomen showed subdiaphragmatic gas but, in view of the length of her history and the relative localization of abdominal signs, it was considered that the leak had sealed off and she was treated conservatively. Barium meal examination subsequently showed gross duodenal deformity.
TREATMENT AND PROGNOSIS

With the exception of the two children in whom perforations were closed all of the children have been treated on a conservative régime so far. In view of the fact that only one of the three patients seen during the first five-year period has remained symptom free it has become the policy during the past three years to admit every child for a period of in-patient treatment as soon as the diagnosis is established. In spite of this three of these children have already required re-admission for recurrent exacerbations of severe pain, which responded to bed rest, diet, antacids, and antispasmodics.

Goldberg (1957) stated that the prognosis in childhood ulceration is good, especially in those cases diagnosed before the age of 10 years. However, Michener et al. (1960), in reviewing 92 child ulcer patients, found that approximately $50 \%$ of those in whom the diagnosis was made at 10 to 14 years had recurrent symptoms, and of these, eight required surgery at some time for pain, stenosis, or haemorrhage. Although the follow-up period in this series is as yet too short for any final conclusions to be drawn regarding the ultimate prognosis, it is felt that a recurrence rate of about $50 \%$, similar to that found at the Mayo Clinic, is to be anticipated, in spite of energetic initial treatment.

\section{SUMMARY}

As the result of a review of all cases of childhood peptic ulceration treated during the period 1953 to 1962 a series of 35 children with duodenal ulceration is presented.

It is believed that insufficient attention has been paid to peptic ulcer as a cause of abdominal pain in childhood, and that it should be considered as a serious differential diagnosis in all children with obscure abdominal symptoms.

It is suggested that childhood ulceration should be treated on an energetic medical régime, including bed rest, as soon as the diagnosis is made, as the available evidence indicates that the prognosis in older children with established chronic ulceration is by no means favourable.

I wish to thank the members of the visiting staff of Sir Patrick Dun's Hospital who allowed me to examine and review their patients. I am grateful to Mr. T. O'Neill and Dr. J. P. R. Rees for critical advice, and to $\mathrm{Mr}$. W. G. Fegan for allowing me to treat, among others, the cases of perforation. Dr. C. L. McDonogh and Dr. H. J. R. Henderson provided radiological confirmation of the diagnosis. 


\section{REFERENCES}

Adler, H. (1907). Gastric ulcer in childhood. Amer. J. med. Sci., 133, 135-141.

Aye, R. C. (1953). Peptic ulcers in children. Radiology, 61, 32-38.

Bird, C. E., Limper, M. A., and Mayer, J. M. (1941). Surgery in peptic ulceration of stomach and duodenum in infants and children. Ann. Surg., 114, 526-542.

Dickey, L. B. (1926). Duodenal ulcers in children. Amer. J. Dis. Child., 32, 872-877.

Fallstrom, S. P., and Reinand, T. (1961). Peptic ulcer in children. Acta paediat. (Uppsala), 50, 431-436.

Goldberg, M. B. (1954). Experience with long-term cortisone therapy in congenital adrenocortical hyperplasia. J. clin. Endocr., 14, 389-408.

Goldberg, H. M. (1957). Duodenal ulcers in children. Brit. med. J., 1, $1500-1502$.
Lorber, J. (1957). Massive haematemesis in a child treated with prednisolone. Ibid., 2, 749.

McAleese, J. J., and Sieber, W. K. (1953). The surgical problem presented by peptic ulcer of the stomach and duodenum in infancy and childhood. Ann. Surg., 137, 334-341.

Michener, W. M., Kennedy, R. L. J., and DuShane, J. W. (1960). Duodenal ulcer in childhood. Amer. J. Dis. Child., 100, 814-817.

Milliken, J. C. (1962). Perforated peptic ulcer in a child with situs inversus. Brit. J. Surg., 49, 457.

Muggia, A., and Spiro, H. M. (1959). Childhood peptic ulcer. Gastroenterology, 37, 715-724.

Oldfield, M. (1932). Chronic gastric ulcer in a boy aged 13. Brit. med. J., 1, 836-837.

Popert, A. J., and Davis, P. S. (1958). Surgery during long-term treatment with adrenocortical hormones. Lancet, 1, 21-34.

Ramirez Ramos, A., Kirsner, J. B., and Palmer, W. L. (1960). Peptic ulcer in children. Amer. J. Dis. Child., 99, 135-148. 